\title{
EFFICIENT WAVELENGTH FILTERS FOR DWDM SYSTEMS
}

\author{
O. Ozolins, V. Bobrovs, G. Ivanovs \\ Institute of Telecommunications, Riga Technical University, \\ Azenes Str., Riga, LV-1048, LATVIA
}

\begin{abstract}
The authors investigate the best parameters of optical filters for dense wavelength division multiplexing (DWDM) systems. The investigation is based on the OptSim 5.0 simulation software using the method for solving a complex set of differential equations taking into account the optical and electrical noise as well as linear and nonlinear effects. It is shown that the bandwidth of optical filter extends as the data transmission speed increases, and that the most efficient are Supergaussian and Raised Cosine optical band-pass filters. It is also revealed that an ASK-RZ 40 Gbit/s data transmission system is impossible to realize with a channel interval less than $50 \mathrm{GHz}$ because of wide spectral density and lower chromatic dispersion tolerance of this modulation format.
\end{abstract}

Key words: dense wavelength division multiplexing (DWDM), optical filtering, nonlinear optical effects (NOEs).

\section{INTRODUCTION}

Technologies and new concepts for optical networking are advancing rapidly as a result of notable progress in all-optical technologies and emerging bandwidth "greedy" applications [1]. Telecom operators are forced, as a consequence, to adapt in the near future their deployed optical fiber communication systems so as to cope with these challenging advances. Deploying "islands" wherein the optical signals benefit from the advantages of transparency may be more feasible than replacing totally the current conventional digital systems by all optical technologies [1]. Therefore it is important to evaluate efficient parameters of wavelength filters in dense wavelength division multiplexing (DWDM) systems.

Wavelength filters (WFs) in optical transmission systems are a special subgroup of physical components defined in such a way that they select or modify parts of the spectrum of a signal. In fact, such filters are defined with respect to the modifications they induce in the power spectral density. In electronic systems, filters play a crucial role in numerous signal processing applications. The WFs perform an equally critical role in the optical domain $[2,3]$.

We will restrict our considerations to the application of WFs in optical networks. Figure 1 schematically shows a global optical network combining local and regional networks via the long haul network. Most of today's network concepts are based on DWDM, which means that wavelength filters are mainly needed in order to route and select specific wavelength channels [2].

It is shown in our simulations that the full width half maximum (FWHM) bandwidth of an efficient optical filter for the amplitude shift keying - non-return to zero (ASK-NRZ) coded optical signals increases with data transmission speed, 
and that the best performing are Supergaussian and Raised Cosine optical bandpass filters. As concerns realization of the amplitude shift keying - return-to-zero (ASK - RZ) $40 \mathrm{Gbit} / \mathrm{s}$ data transmission system, this is impossible to realize with a channel interval less than $50 \mathrm{GHz}$ because of wide spectral density and lower chromatic dispersion tolerance of this modulation format. Good performance is shown by the ASK-Duobinary modulation format; still greater transmission distances for all data transmission speeds are achievable with a differential shift keying non-return-to-zero (DPSK - NRZ) modulation format because of its impressive tolerance for nonlinear optical effects (NOEs).

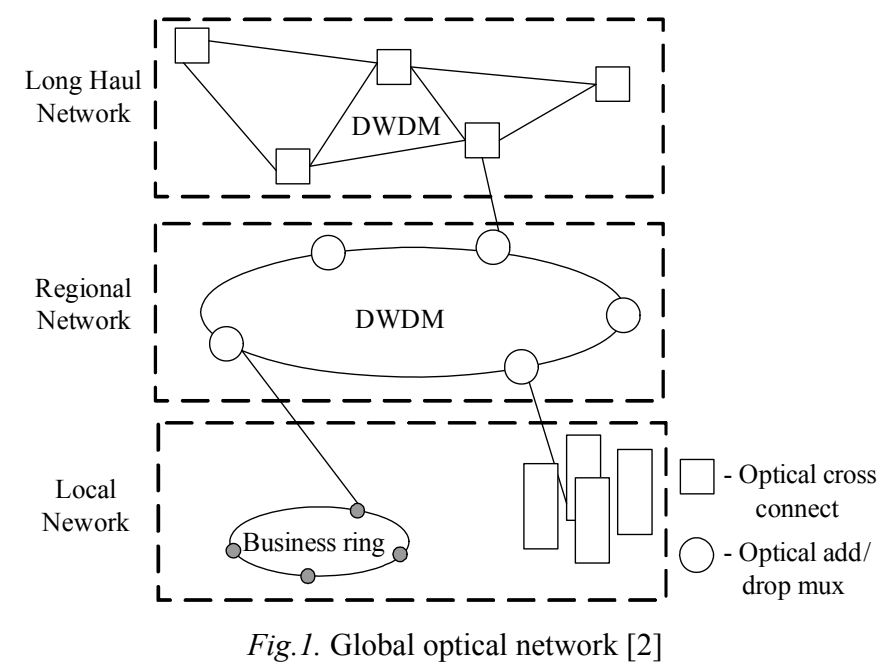

\section{WAVELENGTH FILTERS FOR DWDM SYSTEMS}

Multiplexing and de-multiplexing functions are performed by narrowband filters, cascaded and combined in various ways to achieve the desired result. The filters in optical DWDM transmission systems are classified as: notch filters, power equalization filters, all-pass filters and band-pass filters [1, 3].

Band-pass filters (BPFs) transmit optical power within a definite wavelength window only, and reflect or absorb the rest. The optical BPF bandwidth typically depends on the optical transmission system type [2]. For example, in DWDM the sharpness of the optical BPF amplitude transfer function is of great importance, while in the coarse wavelength division multiplexing (CWDM) it is a minor factor because of a wide frequency interval between the adjacent channels. In these systems the major role is played only by the optical BPF bandwidth, and in the DWDM systems also the shape of the amplitude and phase transfer function should be taken into account, especially for $\geq 10 \mathrm{Gbit} / \mathrm{s}$ systems. Although different kinds of filters are necessary in a DWDM transmission system, band-pass filters are by far the most important, since they are prerequisite for add and drop, multiplex, interleave and routing functionalities which are essentials for a DWDM transmission system realization $[3,4]$.

Travelling through a multiple optical BPF, the optical signal experiences spectral narrowing due to temperature instability of filtering devices and of central frequency of light sources, which could be the main factor of degradation in future transmission systems. That is why we needed to find out the minimal filter's 
FWHM bandwidth which ensures appropriate quality of transmitted data signals in compliance with the International Telecommunication Union (ITU) recommendations. Still, the filter bandwidth is not the exclusive parameter of which we need to be aware. The phase transfer function of optical band-pass filters is of great importance when we transmit information via DWDM transmission systems at very high speed for optical channels [5].

For our research we have chosen the OptSim 5.0 simulation software. We employed three different transfer functions of the optical filter (see Fig. 2) for realization of DWDM system simulation schemes. These functions were chosen because with the Lorentzian optical filter's transfer function we can approximate: Fabry Perrot filters, micro ring resonators; with Raised Cosine: arrayed waveguide grating with a flat top, diffraction gratings, and particular cases of thin film filters and fiber Bragg gratings (with apodization); with Supergaussian: arrayed waveguide gratings with Supergaussian transfer function, and thin film filters with low refraction index modulation [2].
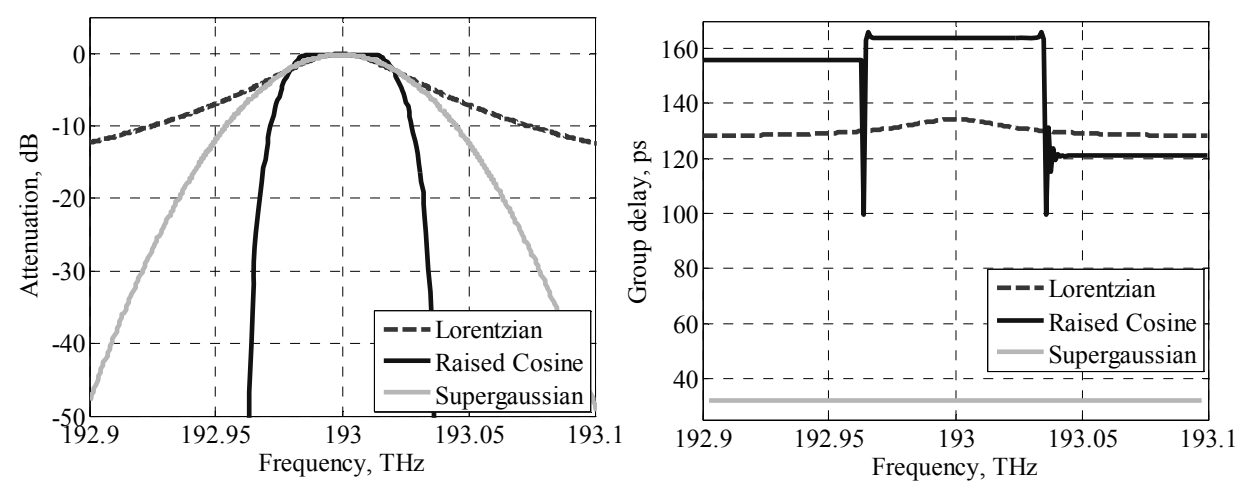

Fig. 2. First-order amplitude transfer $(a)$ and group delay $(b)$ functions of different optical filters shown in the inset (with FWHM bandwidth $0.4 \mathrm{~nm}$ or $50 \mathrm{GHz}$ ).

The graphs are obtained by OptSim 5.0 simulation software.

As is seen from Fig. $2 b$, the greater group delay is for the Raised Cosine optical band-pass filter whose amplitude characteristics are the closest to an ideal filter's amplitude parameters. The ideal amplitude transfer function of a band-pass filter has an almost rectangular shape, providing a perfect transmission (without distortion) of the whole signal within the filter bandwidth, and cutting undesired signals out of the band [2].

\section{MODULATION FORMATS EMPLOYED IN DWDM SYSTEMS}

The capacity of optical communication systems is rising exponentially in order to follow the rapidly increasing demand for data traffic. Limitations due to chromatic dispersion and nonlinearities in the optical fiber become more stringent for higher bit rates. The modulation format describes how the data are coded onto the optical signal. Four properties of an optical signal can be modulated: the amplitude, phase, frequency and the state of polarization. Most systems today use a binary amplitude modulation format with a pulse width equal to the NRZ time slot, 
since very simple transmitters and receivers can be used. However, an increasing stress is being put on alternative modulation formats, particularly the return-to-zero (RZ), Duobinary (Duo) and phase-shift-keying (PSK) [3].

The NRZ modulation format has been the dominant in intensity modulated direct detection (IM/DD) fiber optical communication systems for the last years. The NRZ pulses possess a narrow optical spectrum due to the lower on-off transitions. The reduced spectral width improves the dispersion tolerance, but, on the other hand, it affects the inter-symbol interference (ISI) between the pulses. For that reason, this modulation format is not suitable for high bit rate and long distances. Therefore, NRZ would be a good reference for the purpose of comparison due to its historic application [3].

The RZ pulse occupies just a part of the bit slot, so it has a duty cycle smaller than " 1 " and a broad spectrum. The main characteristic of RZ-modulated signals is a relatively broad optical spectrum, resulting in a reduced chromatic dispersion tolerance and a reduced spectral efficiency. Otherwise, the RZ pulse shape enables an increased robustness to fiber nonlinear effects and to the effects of polarization mode dispersion (PMD). Consequently, a conventional RZ signal is not suited well enough for the use in dense wavelength division multiplexing systems due to its large spectral width. This problem could be solved by using the Duobinary signal, since it has a compact spectrum and a high nonlinear tolerance $[6,7]$.

The Duobinary coding is the simplest of a large code family (called "partial response" codes). Duobinary is a three-level code which substantially reduces the bandwidth occupancy of a signal compared with NRZ coding. This code is in use in some high-speed long-distance systems because of its spectrum narrowing properties. However, this technique requires highly linear electrical amplifiers for three-level signals, a precisely balanced dual-arm modulator, and accurate synchronization between the data modulator and the pulse carver [7].

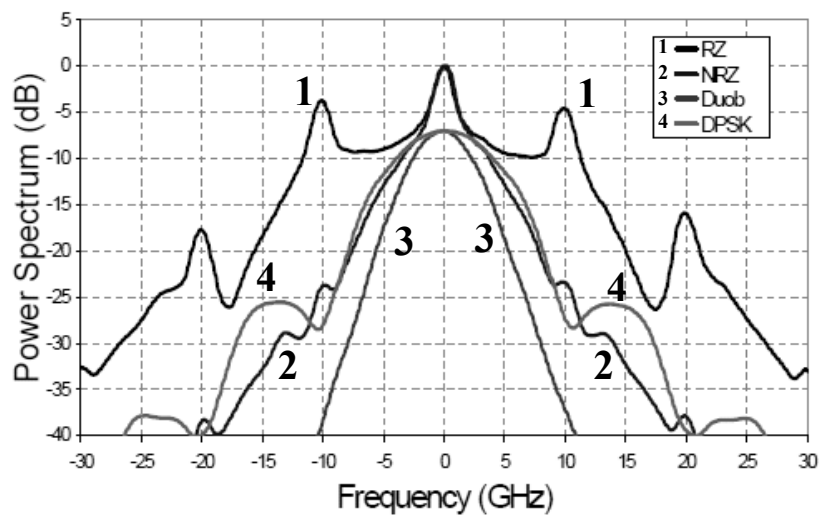

Fig. 3. Measured optical power spectrum density of $10 \mathrm{Gbit} / \mathrm{s}$ optical signals for various modulation formats (shown in inset [8]).

In the early days of optical communications, because of the immaturity of semiconductor laser sources, the optical phase was not stable enough for phasebased modulation schemes. In recent years, with the rapid improvement of single frequency laser sources and the application of active phase locking, PSK becomes 
feasible in practical optical systems. Specifically, the differential phase shift keying (DPSK) is the most often used format. DPSK encodes information using the phase difference between two neighboring bits. A very important characteristic of DPSK is that its signal power is always constant [9]. Figure 3 shows the power spectrum density diagrams for NRZ, RZ, Duo and DPSK signals [8], where the main differences are presented.

\section{SIMULATION SCHEME AND RESULTS}

Realization of efficient data transmission at different modulation and coding formats is highly dependent on accurate evaluation of the optical band-pass filter parameters, because in such modulation and coding formats the power spectrum densities and information distribution are different. Therefore, detailed research into the optical BPF influence on optical signals in DWDM has been carried out. Our research is based on the evaluation of such an important system parameter as the Q-factor using simulation techniques incorporated in the OptSim 5.0 simulation software:

$$
Q=\frac{m_{1}-m_{0}}{\sigma_{1}+\sigma_{0}}
$$

where $m_{1}, \sigma_{1}\left(m_{0}, \sigma_{0}\right)$ are the mean and the standard deviation of the received signal at the sampling instant when a logical " 1 " ("0") is transmitted. For $Q=6(15.56$ $\mathrm{dB})$ the BER value is $\sim 10^{-9}$, and for $Q=7(16.94 \mathrm{~dB})-\sim 10^{-12}[10]$.

In the present work, we analyze the influence of optical filters (see Fig. 2) on different signals in DWDM systems. Figure 4 shows the simulation scheme used in the analysis.

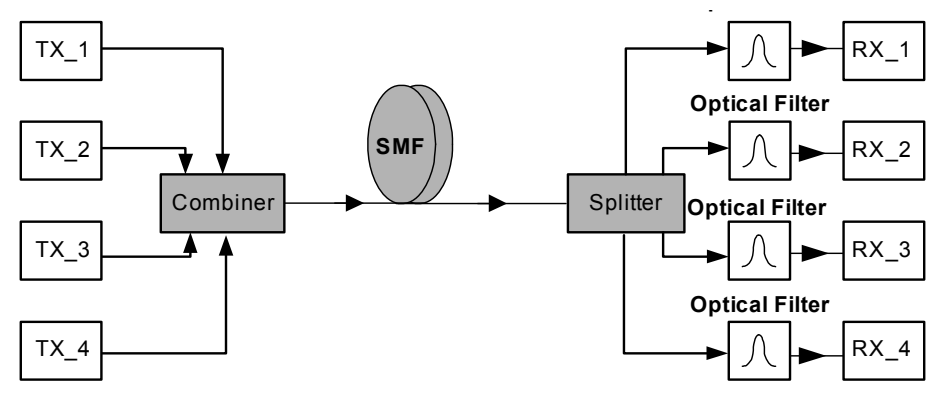

Fig. 4. Four-channel simulation scheme for DWDM transmission with different optical filters.

The simulation scheme contains four channels. This number of channels was chosen by the authors to evaluate the influence of nonlinear optical effects (NOEs): self-phase modulation (SPM), cross-phase modulation (XPM), and four-wave mixing $(\mathrm{FWM})-$ on the performance of the optical filters used $[2,11]$. Figure 5 presents the block diagrams of various transmitter and receiver modifications for NRZ, RZ, Duo and DPSK modulation formats. The transmitter design depends on the employed code and modulation format. The common blocks are: a pseudorandom data source with $2^{31}-1$ bit sequence, a continuous wavelength (CW) laser source, a code former, and an external optical modulator (which varies depending 
on the code and modulation format). The data source produces a pseudo-random electrical signal that carries the information we want to transmit via the optical fiber. Then we use a code former to form the code from incoming pseudo-random bit sequence. The optical pulses are obtained by modulating $\mathrm{CW}$ laser irradiation in the external optical modulator with the previously mentioned bit sequence. After that the formed optical pulses are sent directly to a different length of standard single-mode fiber (SSMF). The receiver block consists of a PIN photodiode for amplitude shift keying or a homodyne coherent detector with a Mach Zhender interferometer for phase shift keying and a Bessel-Thomson electrical filter (whose parameters also depend on those of electrical signal) $[2,3,11,12]$.
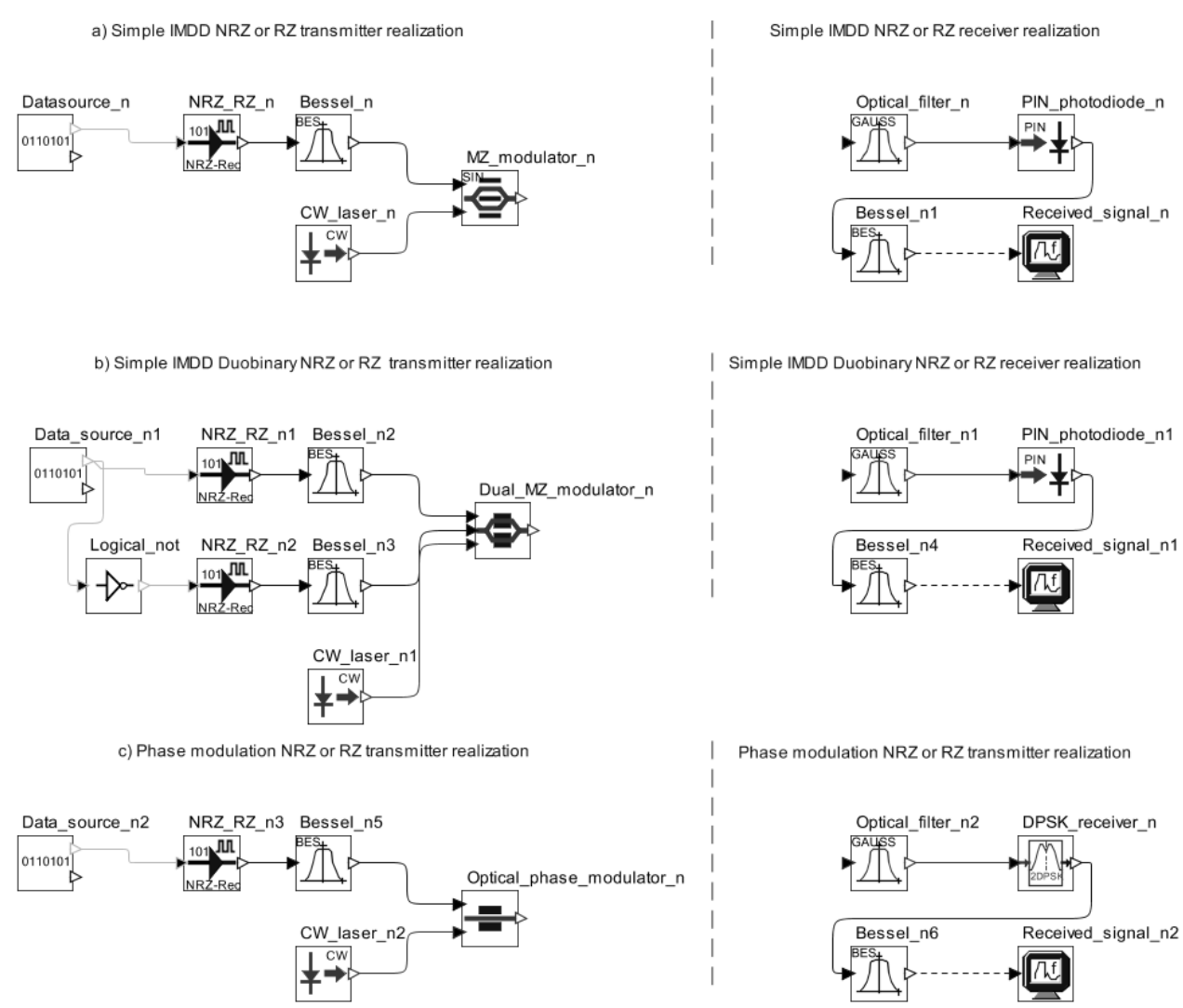

Fig. 5. Block diagrams of transmitter and receiver modifications for different modulation formats [11].

The mentioned above simulation software uses the method of calculation based on solving a complex set of differential equations taking into account optical and electrical noise as well as linear and nonlinear effects. Two ways of calculation are possible: Frequency Domain Split Step (FDSS) and Time Domain Split Step (TDSS) methods. These methods differ in calculations of linear operator $(L)$ : FDSS does it in the frequency domain, while TDSS - in the time domain by calculating the convolution product within a sampled time. The former method is easy to realize, but it however may cause severe errors during simulation. In our simulation we used the second method (TDSS), which, despite its complexity, grants a precise 
result. The Split Step method is used in all commercial simulation tools to perform the integration of the fiber propagation equation:

$$
\frac{\partial A(t, z)}{\partial z}=[L+N] \cdot A(t, z),
$$

where $A(t, z)$ is the optical field;

$L \quad$ is the linear operator that stands for dispersion and other linear effects,

$N \quad$ is the operator that is responsible for all nonlinear effects.

The idea is to calculate the equation over small fiber spans $\Delta z$ by including either the linear or the nonlinear operator. For instance, in the first span only linear effects are considered, in the second - only nonlinear, and in the third - again only linear ones [3,12].
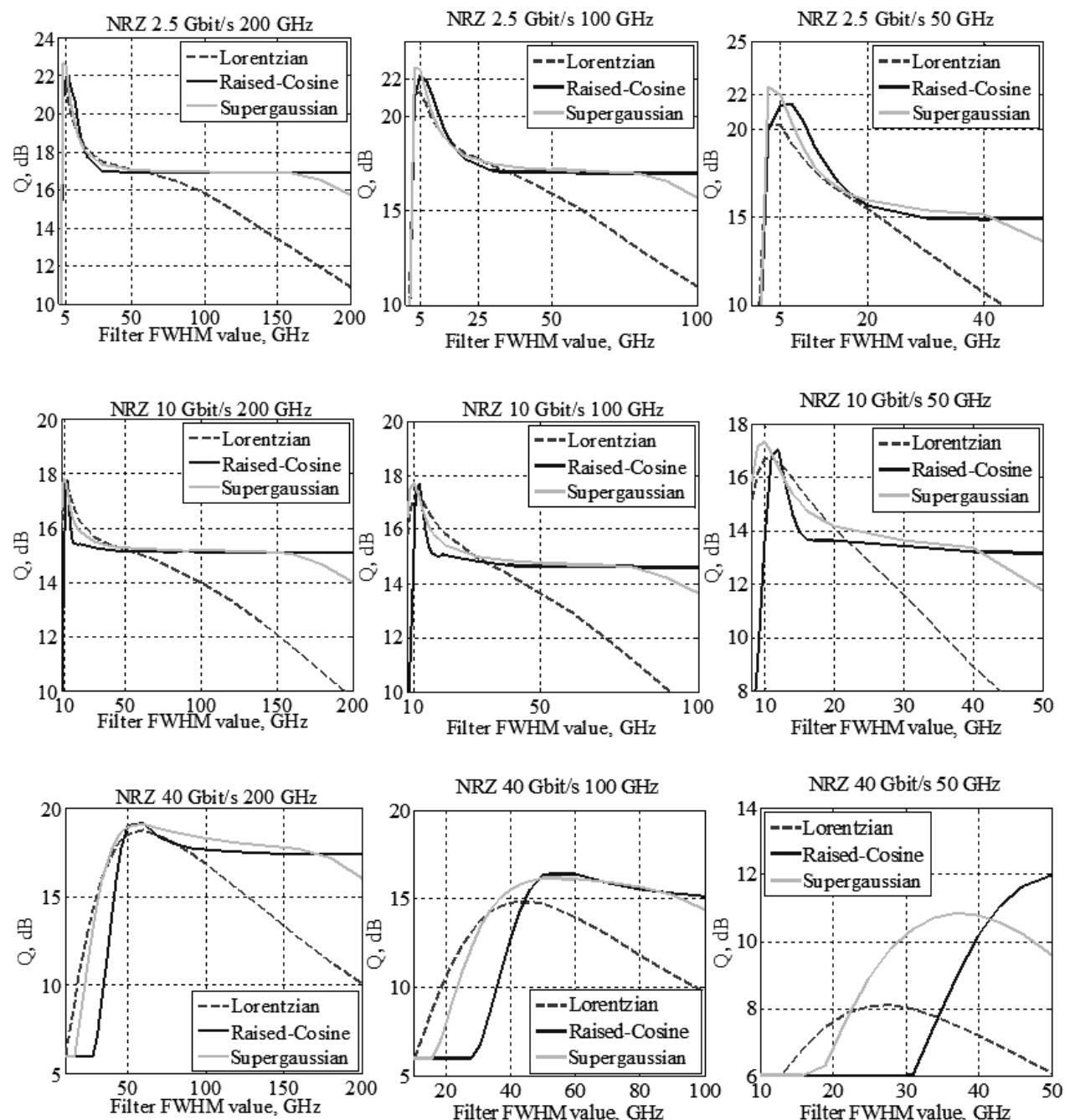

Fig. 6. Q-factor vs. bandwidth for different optical BPFs (shown in the inset) of the ASK-NRZ four-channel 2.5/10/40 Gbit/s DWDM system with $50 / 100 / 200 \mathrm{GHz}$ channel spacing. 
In this research we have calculated the dependences of Q-factor on the FWHM bandwidth of optical band-pass filters with different amplitude transfer functions: Lorentzian, Raised Cosine and Supergaussian, for various simulation setups: with channel spacings 50/100/200 GHZ, data transmission speeds 2.5/10/40 Gbit/s and different modulation formats: ASK and PSK. The main idea of the research was to find out efficient FWHM bandwidth for different simulation scheme setups. For each modulation format and data transmission speed the length of optical fiber was different by the criterion of realization of reliable data transmission (because increase in the data transmission speed results in greater influence of chromatic dispersion and, therefore, also in nonlinear optical effect), but it was kept the same for all channel intervals.

Figure 6 shows the dependence of Q-factor on the bandwidth for different optical band-pass filters: Lorentzian, Supergaussian and Raised Cosine, FWHM bandwidth of an ASK-NRZ four-channel 2.5/10/40 Gbit/s DWDM system with 50/100/200 GHz channel spacing.
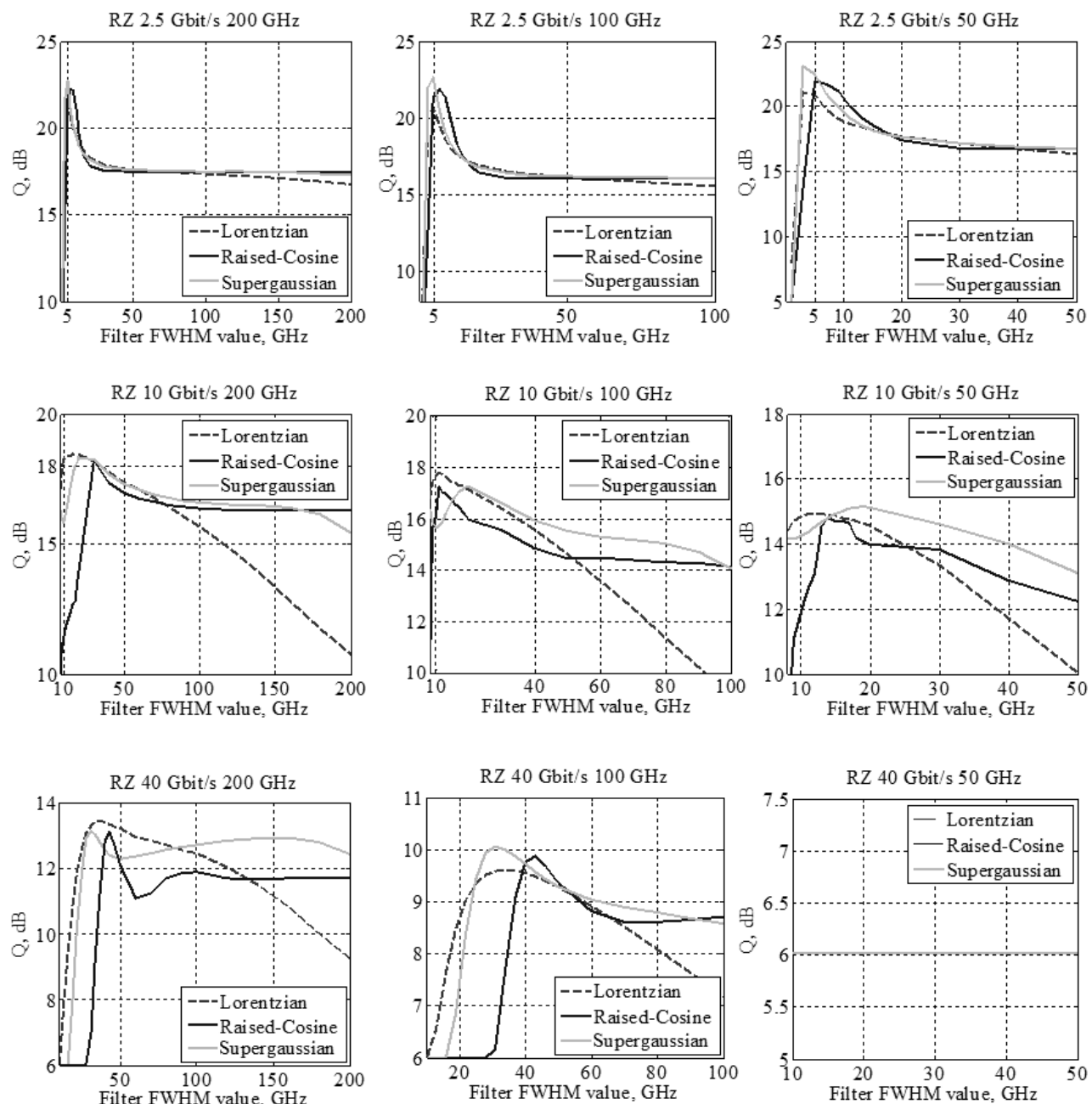

Fig. 7. Q-factor $v s$. bandwidth for different optical BPFs (shown in the inset) of the ASK-RZ four-channel 2.5/10/40 Gbit/s DWDM system with $50 / 100 / 200 \mathrm{GHz}$ channel spacing. 
Our results show that for the ASK-NRZ coded optical signals the FWHM band of efficient filters extends with data transmission speed, and that the best performance is shown by Supergaussian and Raised Cosine optical BPFs. In the best case the FWHM bandwidth values for 2.5/10/40 Gbit/s data transmission speeds are, respectively, $5 \mathrm{GHz}, 10 \mathrm{GHz}$ and $50 \mathrm{GHz}$. In the case of $40 \mathrm{Gbit} / \mathrm{s}$ data transmission speed the $50 \mathrm{GHz}$ channel interval is unsuitable, because Q-factor is below $15.56 \mathrm{~dB}$ (which stands for $\mathrm{BER} \approx 10^{-9}$ ). To realize reliable transmission for this case the channel interval should be greater - more than $50 \mathrm{GHz}$.

For the ASK-RZ four-channel DWDM system (2.5/10/40 Gbit/s, with 50/100/200 GHz channel spacing) dependences similar to those in Fig. 6 are displayed.

As could be expected, the results show similar relationship between the optical filter's FWHM bandwidth and the data transmission speed. All the three BPFs with FWHM bands of 5-6 GHz and 10-20 GHz show good results in realization of $2.5 \mathrm{Gbit} / \mathrm{s}$ and $10 \mathrm{Gbit} / \mathrm{s}$ data transmission speed. At the same time, an ASK-RZ $40 \mathrm{Gbit} / \mathrm{s}$ data transmission system is impossible to realize because of lower chromatic dispersion tolerance of this modulation format. We could not achieve a $50 \mathrm{GHz}$ channel interval for such a system because of wide spectral density of this format.
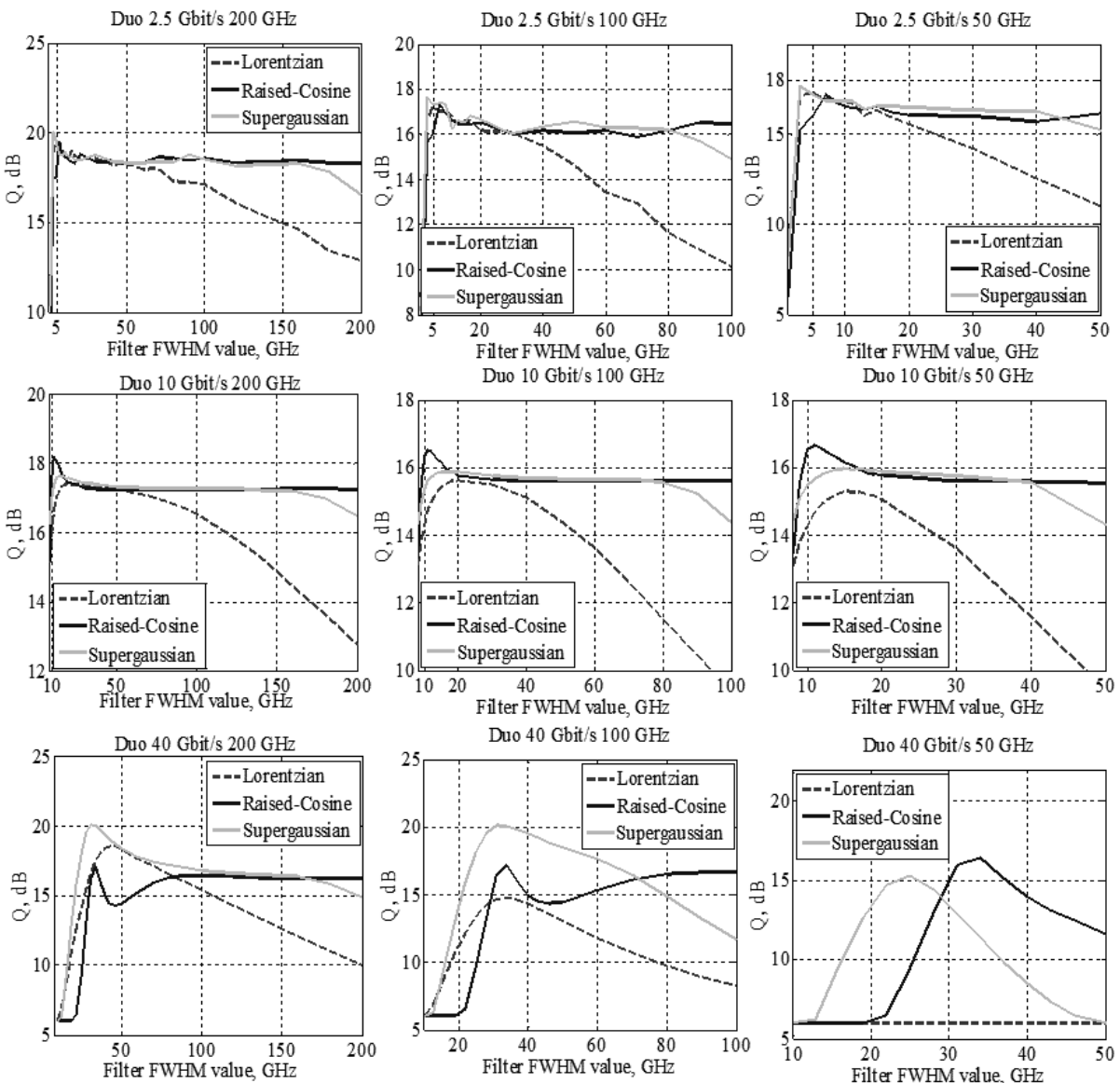

Fig. 8. Q-factor vs. bandwidth for different optical BPFs (shown in the inset) of the ASK-Duobinary four-channel 2.5/10/40 Gbit/s DWDM system with 50/100/200 GHz channel spacing. 
Figure 8 shows the dependence of Q-factor on the FWHM bandwidth for different optical band-pass filters: Lorentzian, Supergaussian and Raised Cosine, of an ASK-Duobinary four-channel 2.5/10/40 Gbit/s DWDM system with 50/100/200 $\mathrm{GHz}$ channel spacing.

As we can see from the results, the best performance for $2.5 \mathrm{Gbit} / \mathrm{s}$ and $10 \mathrm{Gbit} / \mathrm{s}$ data transmission speed is shown by Raised Cosine optical band-pass filter, while for $40 \mathrm{Gbit} / \mathrm{s}$ - by Supergaussian optical BPF. This could be explained by the BPF-induced group delay: the Raised Cosine filter induces a greater group delay than the Supergaussian one. Due to that, the influence of SPM and XPM on the optical signal is more expressed, which especially shows up at higher data transmission speeds. Nevertheless, the ASK-Duobinary modulation format has shown the best performance. This is due to its compact spectral density compared with other modulation formats employed in the research.
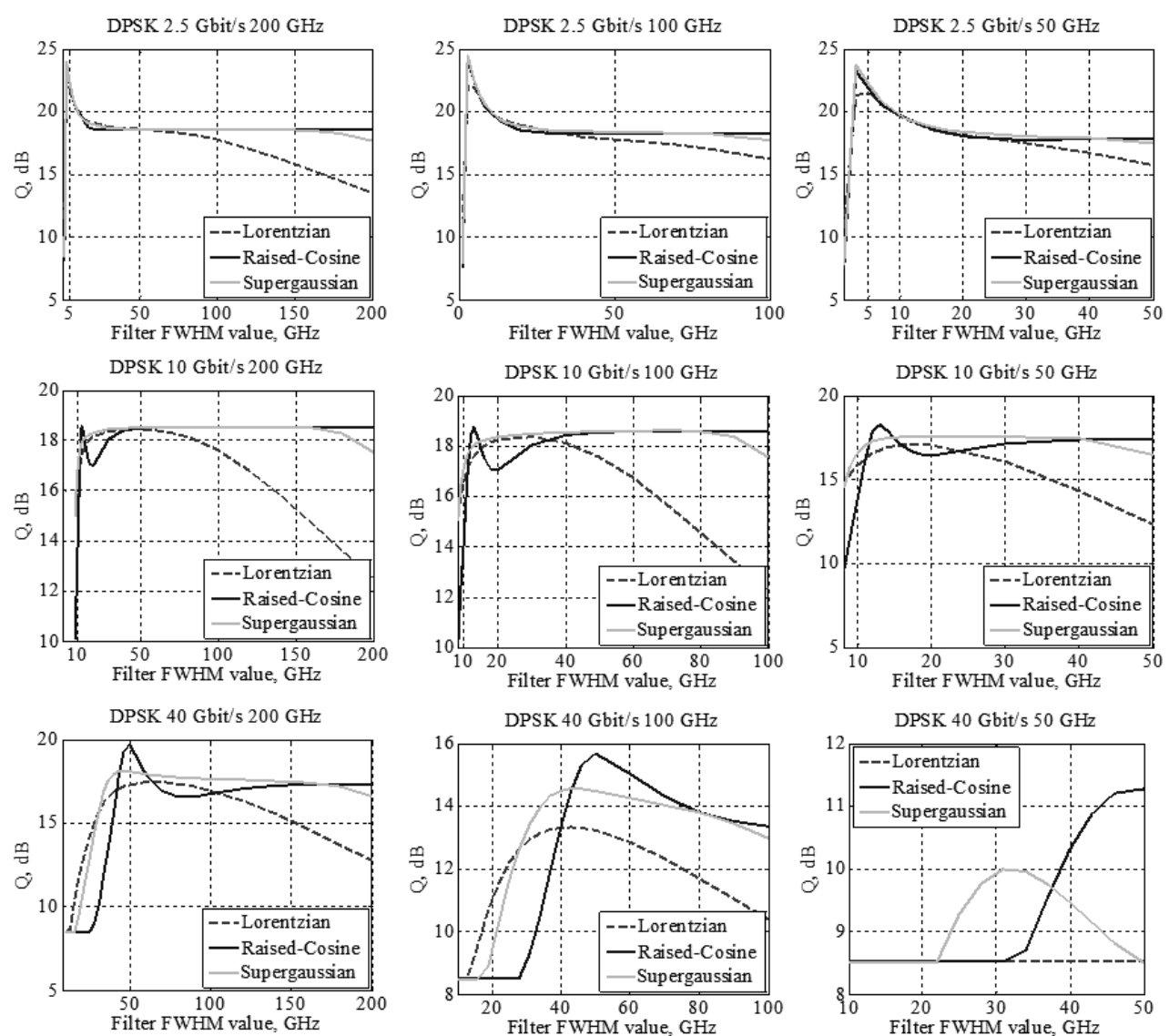

Fig. 9. Q-factor $v s$. bandwidth for different optical BPFs (shown in the inset) of the DPSK-NRZ fourchannel 2.5/10/40 Gbit/s DWDM system with 50/100/200 GHz channel spacing.

Similar to Figs. 6-8, in Fig. 9 the dependences of Q-factor on the FWHM bandwidth are shown for a DPSK-NRZ four-channel Gbit/s DWDM system $(2.5 / 10 / 40 \mathrm{Gbit} / \mathrm{s}, 50 / 100 / 200 \mathrm{GHz})$ at the use of different optical band-pass filters: Lorentzian, Supergaussian and Raised Cosine. The greatest data transmission distances for all data transmission speeds are achieved with the DPSK-NRZ 
modulation format, because of its impressive tolerance for NOEs. The main drawback of this modulation format is its wide spectral density which limits decreasing the channel interval. The Raised Cosine optical BPF showed the best performance for all data transmission speeds with DPSK-NRZ due to its pass-band shape which is the closest to the amplitude transfer function of an ideal optical BPF.

It has been shown that speeding-up the data transmission results in a wider spectral density of modulated signal and efficient FWHM bandwidth for different data transmission speeds. This can be explained through the Fourier transformation time and frequency scaling property: compressing a pulse in the time domain will stretch the power spectrum density and vice versa. Besides, a lower channel spacing between adjacent channels results in greater influence of NOEs which reduce the Q-factor for all FWHM bandwidth values.

\section{CONCLUSIONS}

The applicability of different optical band-pass filters with dissimilar amplitude transfer functions has been evaluated for DWDM systems. Recommendations are given for the next generation of high density WDM transmission. The main conclusions of our simulation are therefore as follows.

- For the ASK-NRZ coded optical signals the FWHM band of an efficient optical filter extends with data transmission speed, with the best performance shown by the Supergaussian and the Raised Cosine optical BPFs. The best case FWHM bandwidth values for 2.5/10/40 Gbit/s data transmission speed values are $5 \mathrm{GHz}, 10 \mathrm{GHz}$ and $50 \mathrm{GHz}$, accordingly. At $40 \mathrm{Gbit} / \mathrm{s}$ data transmission speed the $50 \mathrm{GHz}$ channel interval is unsuitable, since the Q-factor is in this case below $15.56 \mathrm{~dB}\left(\mathrm{BER} \approx 10^{-9}\right)$.

- The ASK-RZ $40 \mathrm{Gbit} / \mathrm{s}$ data transmission system is impossible to realize with the channel interval less than $50 \mathrm{GHz}$ because of spectral density and lower chromatic dispersion tolerance of this modulation format.

- The Raised Cosine optical BPF has shown the best performance for ASKDuobinary WDM transmission systems at $2.5 \mathrm{Gbit} / \mathrm{s}$ and $10 \mathrm{Gbit} / \mathrm{s}$ data transmission speed, whereas the Supergaussian optical BPF - for those at $40 \mathrm{Gbit} / \mathrm{s}$. This could be explained by different BPF-induced group delay: the former filter induces a greater group delay than the Supergaussian optical BPF. Respectively, in the latter case the influence of SPM and XPM on the optical signal is greater, which especially shows up at higher data transmission speeds.

- The greatest data transmission distances for all the speeds are achieved with the DPSK-NRZ modulation format because of its impressive tolerance for NOEs. The main drawback of this format is its wide (compact) spectral density, which limits decreasing the channel interval. The Raised Cosine optical BPF has shown the best performance at all data transmission speeds for the DPSK-NRZ modulation format due to its pass-band shape - the closest to the amplitude transfer function of an ideal optical band-pass filter. 
This work has been supported by the European Social Fund within the project „Support for the implementation of doctoral studies at the Riga Technical University".

\section{REFERENCES}

1. Szodenyi, A. (2004) Optical filter type influence on transparent WDM network's size. Hiradastechnika, (12), 55-58.

2. Venghaus, H. (2006). Wavelength Filters in Fibre Optics. Berlin: Springer, 454.

3. Azadeh, M. (2009). Fiber Optics Engineering. New York: Springer, 374.

4. Agrawal, G. (2001). Nonlinear Fiber Optics ( $3^{r d}$ ed-n). London: Academic Press, 466.

5. Ozoliņš, O., \& Ivanovs, Ģ.. (2010). Evaluation of Band-Pass Filters Influence on NRZ Signal in HDWDM Systems. Lithuanian Journal of Electronics and Electrical Engineering. 4(100) 65-68.

6. Cisco Systems (2008). Cisco Visual Networking Index - Forecast and Methodology 2007-2012. White paper, (1), 1-15.

7. Voges, E., \& Peteramann, K. (2002) Optische Kommunikationstechnik - Handbuch für Wissenschaft un Industrie. Berlin: Springer-Verlag, 1072.

8. Lyubomirsky, I. (2007). Advanced modulation Formats for Ultra-Dense Wavelength Division Multiplexing. White paper, (1), 1-14.

9. Agrawal, G. P. (2002) Fiber Optic Communication Systems $\left(3^{\text {rd }} e d-n\right)$. New York: John Wiley and Sons, 546.

10. OptSim 5.0 User Guide http://www.rsoftdesign.com/.

11. Bobrovs, V., \& Ivanovs, G. (2008). Investigation of Mixed Data Rate and Format Transmission in WDM Networks. Lithuanian Journal of Electronics and Electrical Engineering. 4(84) 63-66.

12. Ozolinšs, O., \& Ivanovs, Ģ. (2009). Realization of Optimal FBG Band-Pass Filters for High Speed HDWDM. Lithuanian Journal of Electronics and Electrical Engineering. 4(92) $41-44$.

\section{EFEKTĪVĀKIE VIL,ŅA GARUMA FILTRI DWDM SISTĒMĀM \\ O. Ozolinş̌, V. Bobrovs, Ģ. Ivanovs \\ Kopsavilku m}

Autori ir noskaidrojuši labākos optiskā filtra parametrus blīvām viļ̣ngarumdales blīvēšanas (DWDM) sistēmām. Pētījumi ir realizēti ar OptSim 5.0 simulācijas programmatūru, kuras izmantotā aprēḳinu metode balstās uz sarežḡìtu diferenciālvienādojumu risināšanu, ņemot vērā optisko un elektrisko troksni, lineāros un nelineāros optiskos efektus. Pētījumā parādīts, ka optiskā filtra joslas platums palielinās līdz ar datu pārraides ātrumu, un noskaidrots, ka Supergausa un Pacelta Kosinusa optiskie joslas filtri ir efektīvākie. Savukārt, ASK-RZ 40 Gbit/s datu pārraides sistēmu nav iespējams realizēt ar kanālu intervālu, kas mazāks par $50 \mathrm{GHz}$, tā plašā jaudas spektrālā blīvuma un zemās hromatiskās dispersijas noturības dēḷ.

06.10 .2010 . 